\title{
DA NOÇÃO LIBERAL DE PESSOA À REFUNDAÇÃo DA CIDADANIA UNIVERSAL: PROVOCAÇÕES PARA PENSAR OS SUJEITOS E SUA EMANCIPAÇÃO PELOS DIREITOS HUMANOS
}

\author{
FROM THE LIBERAL CONCEPT OF PERSON TO THE \\ REFOUNDING OF THE UNIVERSAL CITIZENSHIP: \\ PROVOCATIONS TO THINK ABOUT THE SUBJECTS AND THEIR \\ EMANCIPATION THROUGH HUMAN RIGHTS
}

\author{
Farah de Sousa Malcher \\ Jean-François Yves Deluchey
}

Não exijam da política que ela restabeleça "direitos do indivíduo" tal como a filosofia os definiu. $O$ indivíduo é produto do poder. O que é preciso é "desindividualizar" pela multiplicação e o deslocamento, o agenciamento de combinações diferentes. O grupo não deve ser o liame orgânico que une indivíduos hierarquizados, mas um constante gerador de "desindividualização".

O ANTI-ÉDIPO: UMA INTRODUÇÃO À VIDA NÃO FACISTA - Michel Foucault.

\section{Resumo}

Este texto problematiza a noção de sujeito que fundamenta os direitos humanos. A constatação de que muitas das violações contra esses direitos têm como justificativa o não reconhecimento à diferença, levou à investigação do processo de formação discursiva resultante na concepção de "sujeito universal", centro de gravidade do discurso hegemônico dos direitos humanos. Busca desvelar as relações de poder e efeitos de resistência engendrados por esse discurso, discutindo em que medida o modelo liberal de homem universal, portador de direitos naturais, promove a emancipação dos sujeitos, em especial, das vulnerabilidades sociais. A crítica aos direitos humanos foi a perspectiva norteadora do estudo.

Palavras-chaves: Direito humanos. Sujeitos. Emancipação. 


\section{Abstract}

This article problematizes the notion of subject that is grounded human rights. The fact that many of the violations against such rights have as background the non-recognition of the difference and the various aspects and features of subjectivities, led to the investigation of the process of discursive formation resulting in the conception of "universal subject", center of gravity of the hegemonic discourse of human rights. It is an attempt to uncover the power relations and the effects of resistance engendered by this speech, while discussing to what extent the liberal model of universal man, the bearer of natural rights, promotes the emancipation of subjects, in particular, of the minorities. The critique coupled to human rights was the guiding perspective of this study.

Keywords: Human Rights. Subjects. Emancipation.

\section{INTRODUÇÃo}

Iniciemos com uma pergunta: qual a noção de sujeito/pessoa humana em torno da qual se fundamentam os direitos humanos? As graves distorções e violações relacionadas aos direitos dos homens nas sociedades ocidentais contemporâneas, mormente nas chamadas democracias liberais, em que indivíduos são tratados de maneira desigual no tocante à promoção e ao respeito de seus direitos mais elementares, e onde uma maioria não goza de condições mínimas de existência, nos leva a questionar: quem é, afinal, o sujeito dos direitos humanos? Problematizar de que sujeito se trata quando se fala de direitos humanos parece-nos um desafio necessário diante do fato de que muitos dos atentados contra esses direitos têm como justificativa as diferenças e/ou diversidades em relação a determinado atributo da subjetividade alheia, dissonante da imagem do "sujeito universal", seja por motivo de etnia, raça, sexo, economia, cultura, gênero e outros.

Piovesan (2008) observa que tais violações fundamentaram-se na dicotomia "eu versus o outro", em que a diversidade foi utilizada para aniquilar direitos e conceber o "outro" como um ser inferior em dignidade e direitos, e em situações limites, um objeto negociável e descartável, a exemplo da escravidão, ou ainda exterminável, a exemplo do nazismo. 
Tais acontecimentos têm direcionado a luta por direitos humanos a exigir uma resposta diferenciada em âmbito nacional e internacional, como se determinados grupos de indivíduos, designados "vulnerabilidades" e/ou "minorias" - mulheres, negros, crianças, índios, idosos, homossexuais, etc. - necessitassem de proteção especial e particularizada.

Todavia, a questão paradoxal que se pretende suscitar neste artigo é que os diversos tipos de discriminação social e racismo parecem derivar de uma certa concepção de sujeito universal, moral, absoluto, essencial e identitário, a qual, por sua vez, assemelha-se à noção de sujeito que fundamenta o discurso liberal dos direitos humanos adotado na Declaração Universal de 1948 (DELUCHEY, 2017). A partir dessa percepção, surgem vários desafios: sob a ética aparentemente emancipatória dos direitos humanos, como proteger e emancipar sujeitos, com toda a diversidade de subjetividades e categorias, se a própria noção de pessoa humana que sustenta o discurso dos direitos humanos parece não reconhecer as particularidades dos indivíduos e fomentar, com isso, a consolidação de um racismo de Estado ${ }^{1}$, que se reflete em um consistente padrão de violência, discriminação e exclusão, enraizado nas instituições estatais, privadas e nas práticas das pessoas? Por essa razão, defendemos a necessidade de refletir o conceito de universalidade a partir da questão do sujeito, trazendo ao debate dos direitos humanos outras concepções de subjetividade. Ao que parece, na prática, o reconhecimento estruturalmente discriminatório de direitos, o qual confere a certos indivíduos, considerados inumanos ou de humanidade reduzida, tratamento não condizente com a condição de pessoa, indivíduos estes que destoam da imagem do homem universal, autorizaria o Estado a negar-lhes direitos ou a oferecer-lhes um tipo secundário de cidadania.

Mas os desafios e obstáculos na luta dos direitos humanos não se restringem à questão do sujeito universal. É preciso também indagar as relações de poder que sustentam o discurso hegemônico dos direitos humanos e que conformam as subjetividades, questionando a lógica desse discurso, a fim de desvelar suas estratégias implícitas e/ou veladas. Neste artigo, pretendemos nos afastar da perspectiva tradicional dos direitos humanos, que costuma investigar os problemas decorrentes daquele campo em termos de eficácia/efetividade, para situá-los em termos de ra- 
cionalidade/estratégia (DELUCHEY, 2017), buscando relacionar direitos humanos, práticas de poder e subjetividade. Buscamos refletir, ao final, em que medida o discurso dos diretos humanos promove a autonomia e a emancipação dos sujeitos, em especial, das ditas vulnerabilidades sociais, quanto ao exercício de sua cidadania ativa/primária.

0 presente estudo pretende fundar-se em uma crítica aos "universais" da história, seguindo os passos do filósofo Michel Foucault. Foucault rompeu com o processo histórico que levou à construção jurídica dos universais "Estado", “Soberano", "Sujeito". A crítica ao universalismo foi o instrumento através do qual recortou objetos históricos específicos, dentre eles, o Estado, ou melhor, a prática estatal, a forma pela qual o Estado organiza, define, calcula e racionaliza suas práticas. Ao analisar o governo dos homens e os direitos dos governados na medida em que se apresentam como o exercício do poder soberano, colocou em xeque as noções de "Soberano", “Soberania”, “Povo”, "Sujeito", “Direito”, “Estado” e "Sociedade Civil", todos os universais que a filosofia política utiliza para explicar a prática estatal. 0 método foucaultiano não parte dos universais, e sim do estudo da racionalidade das práticas governamentais, raciocinando os universais a partir dessa lógica.

Acreditamos que a análise concreta das relações dos indivíduos com o Estado, em especial dos indivíduos no campo jurídico, que culminaram no aparecimento da figura do "sujeito universal" titular dos direitos humanos, precisa ser desatrelada do modelo jurídico-liberal de soberania, que pressupõe o indivíduo como sujeito de direitos naturais ou de poderes primitivos. Ao invés de naturalizarmos a lei como manifestação de uma vontade geral, precisamos pensá-la como manifestação fundamental das relações de poder. Em vez de perguntar aos sujeitos o que puderam ceder de si mesmos ou de seus poderes para deixar-se sujeitar, devemos investigar, diz Foucault (2010), como as relações de sujeição fabricam sujeitos, dentre eles, o "sujeito universal" dos direitos humanos.

Esse teria sido seu projeto filosófico quando afirma:

Queria ver como esses problemas de constituição podiam ser resolvidos no interior de uma trama histórica, em vez de remetê-los a um sujeito constituinte. É preciso se livrar do sujeito constituinte, livrar-se do próprio 
sujeito, isto é, chegar a uma análise que possa dar conta da constituição do sujeito na trama histórica (FOUCAULT, 2012, p. 43).

Foucault (1995) refuta aquela ideia de universalidade que circunda a noção moderna de sujeito, compreendido como um ser essencial. Rompe com a ideia jusnaturalista de sujeito enquanto essência, substância, ente. Para o filósofo, somos produtos de uma constituição histórica, atravessada por relações de saber/poder, em que o sujeito aparece como resultado de uma operação de assujeitamento e resistência a um dispositivo. Refuta, assim, o sujeito tradicionalmente concebido na Modernidade como essência, forma fixa e imutável, dotado de razão, o "eu pensante" cartesiano, o sujeito absoluto e totalizado, autônomo e autossuficiente, o sujeito soberano da filosofia iluminista. Não toma o sujeito como essência pré-histórica ou a-histórica, nem como condição primeira de todas as coisas, o sujeito como núcleo central e a partir do qual seriam construídos todos os outros conceitos. Sua investigação levou-o a concluir que sujeito é forma em vez de substância, forma essa que nem sempre é idêntica a si mesma. Há relações e interferências entre as diferentes formas de sujeito, que se exercem sobre ele e também se estabelecem consigo mesmo.

Tendo por base a filosofia foucaultiana do sujeito, nossa intenção é desconstruir o "sujeito universal" dos direitos humanos, pensando-o como produto de uma construção social marcada por relações de poder e efeitos de resistência. Como Foucault, adotaremos uma visão antiessencialista do sujeito e do direito, refletindo-os em sua historicidade e a partir do plano das práticas e estratégias, da trama de relações entre os campos do saber, poder e os modos de subjetivação aos quais o direito não escapa. Em um primeiro momento, analisaremos como os processos resultantes na formação da subjetividade moderna influenciaram a concepção do "sujeito universal", centro do modelo antropocêntrico segundo o qual os direitos naturais do homem nasceram como decorrência da superioridade intrínseca do sujeito racional, figura fundamental da qual deriva uma série de categorias jurídicas e, com elas, o avesso desse sujeito. Depois, refletiremos como a concepção liberal de homem, adotada na Declaração Universal de Direitos Humanos de 1948, influencia a práxis dos direitos humanos. Ao final, apresentaremos reflexões sobre o projeto 
político de refundação da cidadania universal, a partir de um olhar plural e não-substancial sobre os sujeitos com vistas a emancipá-los.

\section{A INFLUÊNCIA DO SUJEITO MODERNO NO SUJEITO UNI- VERSAL DE DIREITOS: A SEPARAÇÃO ENTRE SUJEITOS E NÃO-SUJEITOS}

0 advento da Era Moderna marcou a ascensão do homem como ser dotado de razão, distinto dos demais animais em virtude da sua capacidade de pensamento, exclusiva da natureza humana. A razão torna-se autônoma e desvincula-se do que antes era atribuído ao Divino como forma de explicar os problemas terrenos de maneira científica e racional. Opera-se a transferência do sujeito de Deus ao homem, o ser racional cujo atributo da razão lhe é inerente, nascendo, assim, o sujeito da filosofia moderna, que teve em Descartes e Kant a base de seu constructo filosófico. Na Modernidade, é a tradição racionalista que atribui ao sujeito o papel central como fundamento do conhecimento. 0 sujeito cartesiano é o sujeito do conhecimento, que pensa, duvida e existe, o "eu" consciente de si. A partir do cogito ergo sum, a existência do ser humano foi condicionada à capacidade de pensar. Essa é a ideia contida nos axiomas: "penso, logo existo", "se deixasse de pensar, deixaria totalmente de existir". A concepção de sujeito de direito, por sua vez, advém de todo esse processo filosófico que caracteriza o surgimento do sujeito moderno. As teorias, escritos e estudos que marcam os caminhos desse homem que usa a razão para descobrir, construir, formular e discutir a formação do mundo, são indispensáveis à elaboração de tal conceito. É que o ser pensante vai utilizar sua liberdade para a elaboração de uma constituição jurídica. Tal liberdade, em Kant, seria a liberdade de agir conforme as leis, pois os homens são livres quando causados a agir. A causa das ações nos seres racionais é o livre-arbítrio, o qual pressupõe um sujeito moral e pensante.

Safatle (2013) afirma que o dever moral kantiano representa uma noção central para a avaliação de ações que se queiram morais. Representa a consciência de uma norma a partir da qual as ações particulares 
devem ser avaliadas. Em outras palavras, é a consciência de que as ações só podem ser consideradas morais quando reportadas a uma norma de avaliação, uma normatividade exterior à ação. Kant, nesse sentido, caracteriza o dever a partir de um conjunto de procedimentos formais, procedendo a uma sistematização do dever, que serve como critério de avaliação das práticas pelos seres humanos ligados pela razão. A ação como realização do dever deverá ser categórica, absoluta e universalizável, no sentido de que não pode ser realizada de outra forma. Tal noção será fundamental ao aparecimento do sujeito moderno, pois a definição do dever visava também dar forma às exigências individuais de autonomia, atributo fundamental da subjetividade moderna, na medida em que forneceu uma definição possível do que se entende por "sujeito livre".

Para Safatle (2013, p. 14):

Da mesma forma que o dever será definido como uma norma que me permite tomar distância de minhas próprias ações a fim de avaliá-las, a autonomia será definida como uma lei que dou para mim mesmo em condição de liberdade, transformando-me assim em agente moral capaz de me autogovernar e avaliar meus próprios desejos.

A articulação entre dever e autonomia inaugura a dimensão do dever-ser como o exercício contínuo do autoexame e da comparação entre as ações individuais e os valores e normas que se assumem como ideais. Mas a estrutura procedural do dever, proposta por Kant a partir da sistematização de juízos morais, preleciona que estes independem das experiências pessoais e singularidades, pois se dão previamente a estas, como condições de possibilidade para a experiência da liberdade. A noção moderna de autonomia possui duas características que lhe são fundamentais. A primeira é a sua definição como norma, dotada de universalidade, categoricidade e incondicionalidade, cujo imperativo inspira-se no modelo da norma jurídica. A segunda é a autonomia como expressão de uma vontade que submete outras vontades. É a capacidade reflexiva de autocontrole que funda a identidade do sujeito autônomo. A vontade que expressa a autonomia é a expressão do vínculo do sujeito a uma lei incondicional, fundadora do dever. Disso tudo decorre uma importante noção: "autodeterminação", que, conforme Safatle (2013), é a ideia de 
que somos legisladores de si próprios, o movimento de ser causa de si mesmo - causa sui. 0 sujeito autônomo pode se autodeterminar porque a causa de sua ação é fruto de sua própria liberdade.

Para Kant, se a razão não pudesse postular a realidade objetiva de uma Lei, se a vontade livre visasse apenas à satisfação dos instintos e das necessidades físicas, se os indivíduos seguissem somente a suas explicações fisiológicas sem respeitar o imperativo categórico, não se distinguiria o homem do animal, pois "seria então a natureza que forneceria a lei" (Kant apud Safatle, 2013, p. 27). A distinção entre liberdade e natureza remete à distinção aristotélica entre seres humanos e animais, segundo a qual o homem é o animal político, capaz de pensar, de articular o logos (linguagem/palavra qualificada) e de dominar seus instintos. Em contrapartida, os que divergem deste padrão não podem ser considerados homens, e sim animais detentores da phoné (voz/ruído). Os indivíduos para quem o desejo particular e os impulsos irracionais dominam a vontade foram denominados "patológicos", por serem desejos que se impõem ao indivíduo como um páthos, não se conseguindo comandá-los de maneira autônoma.

Na conclusão de Safatle (2013, p. 28-29):

Dessa forma, se os desejos patológicos e impulsos sensíveis são uma ameaça à minha liberdade e autonomia, então o preço da liberdade será o afastamento daquilo que, em mim, se guia a partir da contingência dos sentimentos, da inconstância das inclinações, do acaso dos encontros com objetos que não são deduzidos de uma lei que dou para mim mesmo.

O modelo kantiano de autonomia divide internamente o sujeito entre vontade e desejo, liberdade e natureza, transcendental e psicológico, em uma concepção clivada da natureza humana. Tal clivagem subjetiva, para Safatle, ainda permanece como referência na filosofia moral contemporânea. Refere-se a Harry Frankfurt (1929), para quem a diferença essencial entre os seres humanos e as outras criatura, seria a existência, nos primeiros, de "desejos de segundo nível", que seriam aqueles decorrentes da capacidade de autoavaliação reflexiva, atributo determinante de um ser dotado de autonomia. Não há dever sem culpa. A experiência da culpa, isto é, a consciência da culpabilidade, é indissociável do sentimento 
de ser virtualmente observado por alguém a quem reconhecemos como autoridade legítima, quem nos fornece uma norma capaz de explicar o que devemos fazer para sermos reconhecidos como sujeitos. "Saber-se culpado é, assim, uma forma de nos certificarmos de que a Lei é para nós, que temos um lugar assegurado diante da porta da Lei" (Safatle, 2013, p. 44). A consciência da culpabilidade é um entendimento que, para Kant, em sua Crítica da Razão Prática, não requer grandes dificuldades, podendo ser exercitado até pela mente mais comum, sem experiência do mundo, ou, no dizer de Safatle, (2013, p. 63): "o entendimento ordinário, este do homem maduro, que ultrapassou a infância e não caiu em loucura, sempre sabe qual é o seu dever".

A exposição sumária da concepção de sujeito para os pensadores modernos tem por escopo mostrar a influência do sujeito cartesiano e kantiano, cuja subjetividade foi definida em torno dos critérios universais fixados pela razão e pela moral, na concepção jurídico-liberal de sujeito, o indivíduo titular de direitos e obrigações, isto é, o sujeito que se sujeita incondicionalmente à norma (jurídica, moral, disciplinar, biopolítica ou de consumo), independentemente do seu desejo (distinto da vontade e da razão). As transformações ocorridas na Modernidade mudaram a concepção de homem, fazendo com que passasse de "dominado" (objeto) para o centro da dominação (sujeito). Por outro lado, todos os "irracionais" que não passavam pelo crivo da "norma" passaram a ser vistos como objetos ou "não-sujeitos". É que a liberdade de pensar gerou responsabilidade perante os outros, assim como a exigência, por parte dos outros, do cumprimento de seus deveres. Enquanto a noção de dever foi delineada em torno de um forte apelo moral, a relação jurídica foi definida como um direito-dever entre seres humanos e o sujeito de direito, único capaz de direitos.

Para Bomfim (2003):

Existe, dessa forma, um ponto de conformidade entre a concepção de Kant e a dogmática jurídica positivista, pois ambos consideram apenas o homem, devido à sua condição de ser racional, como único capaz de estabelecer uma relação direito-dever. Nesse contexto, nada além do Ser racional pode ser considerado como Sujeito de Direito, pois são apenas objetos, se levado em consideração o fato de que, numa relação jurídica são incapazes de 
estabelecer comportamento jurídico com os homens. [...] A incapacidade por parte de outras categorias em contrair direitos e obrigações faz com que se tornem não Sujeitos, e sim Objetos de Direito.

O sujeito de direito, portador universal e abstrato de direitos e deveres, foi definido em torno da norma. Por "norma" e "normalização", devemos entender como os domínios ou os campos definidos por um conjunto de saberes, dentre os quais a Medicina, a Psiquiatria e o Direito, que implicaram a formação da subjetividade moderna e que definiram uma ordem do "normal", do desejável e do calculável nas sociedades ocidentais. A norma caracteriza a forma que tais saberes assumiram na Modernidade, tendo como traço distintivo o caráter normativo que define e separa os objetos e sujeitos por eles estudados em categorias fixas, como as do "normal/anormal", "cidadão/inimigo". Em Foucault, o tema da norma aparece intrinsecamente relacionado à patologização da loucura pela Psiquiatria, na medida em que, a partir daí, se instituiu um critério normativo de classificação e de separação das subjetividades em torno do normal e do patológico, de onde se infere que o "normal" veio antes da norma, ou que a norma foi dele deduzida. Em História da Loucura, observa Fonseca (2002), a norma aparece como princípio de exclusão ou de integração baseada em saberes científicos e anunciando critérios de verdade, cujo valor pode ser restritivo ou constitutivo. Aparece, ainda, como "norma de poder", fixando para o sujeito as condições de sua liberdade, segundo regras externas ou leis internas.

Com Descartes, a loucura tornou-se desrazão, consolidando-se uma consciência crítica do louco, fundamentada menos em uma percepção científica que moral. Operou-se a cisão do louco dos sujeitos "normais". 0 louco é associado àqueles que, de alguma forma, transgridem as normas morais, sociais e jurídicas, ao lado do criminoso, da prostituta, do estrangeiro, do mendigo, do homossexual e de todos os heterogêneos que não se identificavam com a figura autoidêntica do sujeito moderno. Forma-se uma consciência médico-jurídica acerca dos "irracionais", associada à falta de identificação com o sujeito universal e moral. Tais indivíduos passam a ser analisados pelas implicações que podem causar no sistema de obrigações. São percebidos a partir de uma referência fundamental 
ao sujeito de direito, representando o seu avesso: o sujeito de direito alienado. Manifestam o erro, o delírio, o irreal, o inexistente, o desumano, o insensato, aquilo em que a consciência de todos não consegue reconhecer-se, aquilo que não está baseado nela, portanto, aquilo que não tem o direito de existir: o "não-sujeito". Essa forma reificada de homem passa a ser vista como perigosa e/ou inútil à sociedade autoidêntica, afinal, o "não-sujeito" é aquele que rompe com o pacto social que o liga aos demais, o "estrangeiro" irredutível às leis e às normas gerais, que entra em guerra contra a sua própria sociedade e, desse modo, "a punição não deve ser a reparação do prejuízo causado a outrem nem o castigo da culpa, mas uma medida de proteção, de contraguerra que a sociedade tomará contra este último" (Foucault, 2015, p. 31). Por destoarem da imagem do sujeito universal titular de direitos, não há como reconhecer direitos aos "não-sujeitos", o que, por sua vez, legitima a neutralização/exclusão dos "diferentes" pela criação de marginalizações sociais e penais.

O legado antropocêntrico moderno, observa Bragato (2014), atribuiu à racionalidade o caráter distintivo do humano, colocando-o em uma posição de superioridade. Daí decorre o fato de a dignidade humana ter se tornado indissociavelmente ligada à ideia de racionalidade, o que é facilmente observado quando se verifica o oposto, as formas rotuladas irracionais, porque primitivas, selvagens ou inferiores. Por outro lado, a partir do momento em que a sociedade burguesa se define como um sistema de relações entre indivíduos que possibilita a produção e permite maximizá-la, dispõe também de um critério de designação de seu inimigo: "qualquer pessoa que seja hostil ou contrária à regra da maximização da produção" (Foucault, 2015, p. 49). Os indivíduos passam a ser valorados em termos de "utilidade" ao capitalismo em ascensão, em uma sociedade que condenava e rejeitava todas as formas de ociosidade, inutilidade e incapacidade para o trabalho. Interessante, neste aspecto, a associação que Kashiura Jr. (2012) faz entre sujeito de direito e capitalismo, identificando aquele como o reflexo filosófico da realidade social e econômica de sua época. É que o pleno desenvolvimento das relações burguesas exigiu a forma "sujeito de direito" em sua dimensão universal. Em Hegel, a concepção de sujeito universal, igualmente capaz de investir as coisas em sua propriedade e de dispor livremente de si e de sua força de trabalho como 
mercadoria, desde que por vontade própria, emerge como a representante jurídica do pensamento burguês. A universalização do sujeito de direito é, ao mesmo tempo, a universalização da circulação de mercadorias, e ambas combinadas permitem a troca irrestrita e o pleno desenvolvimento da personalidade jurídica no espaço da circulação. “0 sujeito de direito é alçado à condição de portador de uma vontade livre apenas porque o processo de troca assim exige" (KASHIURA JR., 2012, p. 122).

A seguir, analisaremos como a concepção liberal de pessoa humana adotada na Declaração Universal de Direitos Humanos de 1948 influencia a práxis dos direitos humanos, produzindo efeitos de poder e resistência.

\section{O SUJEITO UNIVERSAL E SEUS IMPACTOS NOS DIREITOS HUMANOS}

A concepção de que as subjetividades estão acopladas em torno de um modelo de "sujeito universal", absoluto, autoidêntico, racional, pensante, moral e autônomo - este último porque subjaz seu arbítrio ao dever e à norma -, exige dos sujeitos comportamentos também universais, o que, por sua vez, reflete diretamente nos direitos humanos daqueles que se afirmam "diferentes" e que postulam o direito à diferença. Prova disso são os impactos dos processos de descolonização nas declarações e convenções de direitos humanos e na própria concepção desses direitos.

Clavero (2014), em seu Derecho global. Por una historia verosímil de los derechos humanos, remonta ao contexto político da votação final da Declaração Universal de 1948 e da elaboração do artigo terceiro, o qual versa sobre a igualdade de direitos e sua possibilidade de extensão aos habitantes de territórios coloniais não autônomos. A Iugoslávia propôs uma emenda àquele artigo, fazendo nele constar expressamente a palavra "colônias", de forma que a previsão de igualdade de direitos fosse extensiva aos povos e minorias (cláusula de inclusão colonial). Tal emenda, entretanto, foi reprovada, sendo a proposta de alteração aprovada na Assembleia de autoria do Reino Unido, potência reconhecidamente colonizadora. Diante disso, questiona o autor: "Como garantir direitos humanos em um mundo onde, todavia, predomina o colonialismo e outras políticas racistas por parte 
dos mesmos Estados que acabam de constituir as Nações Unidas?" (tradução nossa, p. 21). A Declaração de 1948 silenciou em relação aos direitos dos povos e minorias colonizados, como se a dependência política a que são submetidos e o estranhamento cultural que enfrentam em nada afetasse o gozo de direitos com alcance universal e em pé de igualdade, princípios basilares daquele documento. Para Clavero (2014), o embaraço à cláusula de inclusão colonial iugoslava evidencia o propósito da Declaração de realizar a exclusão, o condicionamento e a modulação dos direitos dos povos colonizados. 0 colonialismo subsiste na Declaração e a cláusula de inclusão colonial, em verdade, acusa a sua exclusão.

Mais de uma década depois, instrumentos como a Declaração sobre a Concessão de Independência aos Países e Povos Coloniais de 1960 e os Pactos de Direitos Civis e Políticos, e de Direitos Econômicos, Sociais e Culturais de 1966, impactaram a concepção de direitos humanos naturalizada na Declaração Universal, de forma a reforçar o direito de livre determinação de todos os povos e sua incompatibilidade com a continuidade do colonialismo. Os movimentos de descolonização colocaram em xeque, principalmente, os tão alardeados princípios da igualdade e da universalidade. Como aceitar que todos são iguais e gozam dos mesmos direitos, se o exercício de tais direitos ocorre de maneira desigual? É que segundo Clavero (2014), não estão abrangidos na concepção de direitos humanos os sujeitos não emancipados ou que fogem ao conceito de rights como capacidades humanas, em benefício de determinados sujeitos. Os direitos dos sujeitos colonizados situam-se em uma posição mais de princípio negociável entre colonizador e colonizado, por determinação unilateral da metrópole dominante. A concepção original da Declaração Universal entende como direitos humanos aqueles baseados na natureza humana, e não em alguma cultura em particular, pois desta decorrem direitos unilaterais, condicionados e suscetíveis de serem suspensos ou modulados.

Os tratados que sucederam à Declaração Universal permaneceram, assim como ela, neutros e inoperantes em relação à efetividade dos direitos, como é o caso da Convenção sobre Genocídio, importante para a garantia de direitos dos sujeitos colonizados, o que leva Clavero a questionar: "De que serve a Declaração Universal?"2. A Declaração resultou em uma concepção de direitos humanos universais que não abrangeu os 
direitos dos povos nem das minorias, traduzindo, com isso, a perspectiva do sujeito colonizador. Prova disso foi a ausência de representação dos colonizados na Assembleia Geral e nas instâncias das Nações Unidas. Mas a pressão dos movimentos sociais resultou na adoção de uma política de descolonização, que teve como principal consequência normativa o Pacto de Direitos Civis e Políticos. Seus protagonistas principais foram os povos colonizados representantes da população afroamericana dos Estados Unidos, denunciando que dentro dos EUA existem grupos diferenciados que, embora sejam objeto de políticas específicas, não necessariamente são sujeitos de direitos. É que o colonialismo europeu e euroamericano criou toda uma cultura jurídica e política de abstração de sujeitos no tocante ao reconhecimento de direitos, em que "proteção" pode perfeitamente significar dominação, e o universalismo, por meio da naturalização do social, do humano e do arbitrário, esconde seus efeitos de dominação e hierarquização. Para Clavero (2014), o colonialismo gerou um verdadeiro direito do inimigo, um direito que pode negar direitos, constituindo-se em um direito de exceção. Por sua vez, a Declaração Universal consolidou a concepção colonial de sujeito e de direitos como mecanismos de dominação, atropelando liberdades e ignorando garantias, combinando um direito concessivo ao colonizador e omisso e condicionável ao colonizado. Disto resulta um sujeito sem direitos e inimigo em potencial. Podemos, portanto, afirmar que os processos de descolonização impactaram a concepção de sujeito universal e de direitos humanos, no sentido de colocar em xeque o axioma da universalidade indistinta e abstrata, que na prática, conserva, alimenta, multiplica e potencializa efeitos discriminatórios ao excluir as minorias não abarcadas por este conceito.

O exemplo mais emblemático disto é o direito de intervenção. Wallerstein (2007) nos mostra como essa prática, desde o início das missões civilizatórias, sempre esteve calcada em "valores universais" como justificativa para a expansão dos Estados europeus e construção da economia-mundo capitalista. 0 debate entre Bartolomé de las Casas e Guinés de Sepulveda ${ }^{3}$ no século XVI, no contexto da conquista espanhola das Américas, é bem nítido nesse sentido. 0 argumento de que há pessoas naturalmente bárbaras, brutas, simplórias, iletradas e não instruídas, incapazes de aprender qualquer coisa que não seja seus pró- 
prios vícios, aconselha que sejam governadas por outros. 0 modelo de homem sacralizado em uma certa "lei natural", que exige determinados tipos de comportamento universal, e o imperativo de impedir o mal e promover a equivalência/homogeneização das subjetividades, foram e ainda são fundamentos para legitimar as intervenções. No século $\mathrm{XX}$, época pós-colonial, a linguagem retórica que passou a justificar as intervenções foi a dos direitos humanos universais, diz o autor. Chama atenção para a ambiguidade moral do discurso universalista, que justifica, ao mesmo tempo, a defesa dos direitos dos chamados "inocentes" e a exploração material dos fortes que a consagram, atacando os crimes de alguns e passando por cima dos crimes de outros. Tal ambiguidade integra o arcabouço dos valores aceitos como universais, mas que, para Wallerstein, são criações sociais dos estratos dominantes. 0 critério é do universalismo europeu, o conjunto de doutrinas e pontos de vista éticos que derivam do contexto europeu e ambicionam o status de valores universais globais, "A criação de tais valores é o maior empreendimento moral da humanidade" (2007, p. 60).

As reflexões de Clavero e Wallerstein são corroboradas por Donnelly (2007), quando afirma que ao mesmo passo em que a concepção hegemônica de direitos humanos consolidou-se desde o término da Guerra Fria, ganharam espaço as perspectivas pós-colonialistas e os argumentos antiuniversalistas, em combate ao neoimperialismo dos argumentos que sustentam a universalidade ontológica e substancial. Os discursos contra-hegemônicos propiciam reflexões um tanto incômodas, pois nos fazem pensar se os direitos humanos, hoje, constituem mais um problema que uma solução. Para este autor, algumas das versões do universalismo, como a antropológica e ontológica, são teoricamente e empiricamente indefensáveis, ante os efeitos de dominação que produzem. Tais discursos, ao ignorarem todas as formas de diversidade, particularidade e relativismo, elevam o nível de abstração dos direitos humanos a ponto de inviabilizarem suas consequências práticas, concretas. A forma de universalismo consagrada na Declaração Universal pode até prever que direitos humanos são universais, todavia, a promoção e concretização desses direitos não ocorre de maneira universal. Há a sobreposição de um consenso acerca da ideia de direitos humanos, o qual considera os direitos praticados por 
diversos países africanos e asiáticos incompatíveis com os direitos humanos universais. Trata-se de um consenso construído mais por coerção que de modo voluntário, não deixando margem para relativismos.

Santos (2013), por sua vez, chama atenção para as ilusões e tensões geradas pelo discurso hegemônico dos direitos humanos, o qual nos leva a crer que a trajetória de consagração desses direitos foi linear, desprovida de conflitos e lutas, assim como de interesses e relações de poder, remetendo-nos à ideia de consenso acerca dos direitos humanos universais. Tal consenso, em verdade, constitui uma doxa, um senso comum assentado em uma variedade de "ilusões", que, por sua vez, provocam "tensões", a partir das quais é possível identificar certos problemas. No que diz respeito aos diversos tipos de sujeito, refere a tensão entre o "humano e o não humano". A universalidade dos direitos humanos sempre conviveu com a ideia de "deficiência originária" da humanidade, a qual implica dizer que nem todos os seres com fenótipo humano são plenamente humanos, razão pela qual não devem se beneficiar do estatuto e da dignidade conferidos à humanidade. Isso explicaria a escravatura e a possibilidade de defender, a um só tempo, a liberdade e a igualdade dos cidadãos (2013, p. 77): "porque subjacente aos direitos humanos está a linha abissal [...] por via da qual é possível definir quem é verdadeiramente humano e, por isso, tem direito a ser humano, e quem o não é e, por isso, não tem esse direito". Esta seria a inversão dos direitos humanos.

Ainda nas palavras do autor:

A exclusão de alguns humanos que subjaz ao conceito moderno de humanidade precede a inclusão que os direitos humanos garantem a todos os humanos. A concepção ocidental, capitalista e colonialista da humanidade não é pensável sem o conceito de sub-humanidade. Ontem como hoje, mesmo que sob formas distintas (SANTOS, 2013, p. 77).

Diante de tais considerações, questionamos: o que o universalismo hegemônico quer naturalizar em relação aos sujeitos e com que pretensões de poder? Em outras palavras, qual a racionalidade desse discurso e seus efeitos nas subjetividades? Para Bragato (2014), a problematização em termos de racionalidade demonstra que, por detrás da aparente neutralidade do discurso universalista, subjaz um projeto de invisibilidade 
e opressão humana, reforçado pela ideia de raça e pelo exercício de um poder de matriz colonial. A nosso ver, o universalismo engendra dois sujeitos distintos de direitos humanos: um cuja subjetividade atende aos critérios normativos da razão e da moral e ao padrão de vida neoliberal e eurocêntrico esperados dos sujeitos universais, os quais gozam de cidadania ativa/primária, com direito de participação nos processos decisórios de seu país, da comunidade política, do mercado e etc.; e um outro que fica de fora desse conceito de universalidade e que precisa ser "protegido", dominado, neutralizado, controlado. Esse tipo de homem, que deixa de ser sujeito para se tornar objeto de direitos humanos e de intervenções humanitárias, aproxima-se da figura do homo sacer descrita por Agamben (2010), o ser vivente que está no mesmo patamar dos animais e cuja vida é nua, despolitizada, desqualificada, isolada politicamente, situada à margem da ordem jurídica que a ele não se aplica. Sua vida, embora insacrificável, é plenamente matável, e caso venha a ser morto, este fato não configura homicídio, pois sua existência não constitui um bem jurídico.

Segundo Agamben (2010), aí restaria caracterizada a ambiguidade ou polaridade da democracia: constituída desde a origem sob uma intensa vocação biopolítica, na medida em que assegura, a um só tempo, a proteção e a garantia das liberdades do indivíduo, elevando-o à categoria de cidadão e sujeito soberano de direitos; de outro lado, sujeita-o à condição de mero corpus, de sacer, a um "estado de exceção permanente", em que a excepcionalidade passou a vigorar como regra. Trata-se da situação de certas pessoas que, ao longo da história, foram e ainda são privadas de quase todos os direitos e liberdades atribuídas ao ser humano, mas que, biologicamente, continuam vivas, situando-se em uma zona-limite entre a vida e a morte. Refere-se à figura do refugiado para ilustrar o rompimento entre o homem e o cidadão, a separação para fora do contexto da cidadania, voltando à condição de vida nua, em que o humanitário se descola do político. Em suas palavras:

É suficiente um olhar sobre as recentes campanhas publicitárias para arrecadação de fundos para os refugiados de Ruanda, para dar-se conta de que a vida humana é aqui considerada [...] exclusivamente como vida sacra, ou seja, matável e insacrificável, e somente como tal feita objeto de 
ajuda e proteção. Os 'olhos suplicantes' do menino ruandês, cuja fotografia se desejaria exibir para obter dinheiro, mas que 'agora está se tornando difícil encontrar vivo', são o índice talvez mais significativo da vida nua no nosso tempo [...]. (AGAMBEN, 2010, p. 130).

Em Who is the Subject of the Rights of Man?, Rancière (2004) observa que nos últimos dez anos do século XX, a nova definição da humanidade, livre do totalitarismo utópico, tornou-se palco de novas crises de conflitos étnicos e chacinas, fundamentalismos e movimentos raciais ou xenofóbicos. 0 território do pós-histórico e da humanidade pacífica provou ser o território de novas figuras do "desumano", e os direitos humanos revelaram-se ser os direitos do "sem direitos", do povo forçado a abandonar seus lares e terras, ameaçados por chacinas étnicas. Esses direitos significavam cada vez mais os direitos das vítimas, daqueles que eram incapazes de fazer valer qualquer direito, ou mesmo qualquer requerimento em nome deles. Os direitos desses povos tiveram que ser pertinentes a outros, às custas de fragmentar as estruturas do Direito Internacional em nome de um novo direito de interferência humanitária, que acabou acarretando o direito de invasão. Questiona o autor: "o que se esconde atrás dessa estranha mudança de Homem para Humanidade? E de Humanidade para Humanitário? Não haverá uma certa discriminação nas declarações de tais direitos? (TRADUÇÃO NOSSA). Para Rancière, o verdadeiro tema desses direitos tornou-se os "direitos humanos". Levanta a suspeita de que o homem dos direitos humanos foi uma mera abstração, porque somente os direitos verdadeiros eram os direitos dos cidadãos, os direitos pertinentes à comunidade nacional como um todo. Os direitos humanos seriam os direitos daqueles que nada mais são que seres humanos per si, os direitos "dos que não têm direitos", dos apolíticos, os direitos dos "desumanos".

\section{CONCLUSÃO: Direitos humanos, universalidade e eman- cipação: existe uma saída viável?}

É preciso recusar a divisão de tarefas que, com frequência, nos propõe: aos indivíduos, de se indignar e falar; aos governos, de refletir e agir. [...] A vontade dos indivíduos deve inscrever-se em uma realidade cujo mo- 
nopólio os governos quiseram reservar para si mesmos - esse monopólio que é preciso arrancar pouco a pouco e a cada dia.

FACE AOS GOVERNOS, OS DIREITOS HUMANOS - Michel Foucault.

De acordo com Rebouças (2015), as insuficiências da teoria tradicional dos direitos humanos em encarar as diferenciações da subjetividade e de promover a autonomia e emancipação dos sujeitos, evidenciam a necessidade de substituir o apelo ao universal e ao essencial por formas mais dissonantes e singulares de subjetivação. Com base nessa premissa e diante das contribuições dos autores até aqui estudados quanto aos efeitos de dominação nos direitos humanos provocados pela hegemonia do sujeito universal, trazemos como considerações finais a este artigo uma reflexão sobre a possibilidade de emancipar sujeitos pela via dos direitos humanos, a partir de uma dimensão ética e política diferente, para além das cartas e tratados. É que a hiperinflação de discursos sobre direitos humanos, todavia esvaziados de capacidade de transformação social e emancipação dos sujeitos envolvidos, indica, diz a autora, o distanciamento concreto do potencial emancipador e criativo de tais discursos, no sentido de garantir uma vida digna, empoderando e viabilizando as subjetividades. Acredita que é em parte porque direcionado a um sujeito universal, que os diretos humanos tornam-se insensíveis às dores e aos contextos regionais e pouco efetivos quanto às lutas sociais. Sugere a necessidade de abandonar a subjetividade moderna em favor de uma visão mais descentralizada e multidimensionada do sujeito, como entidade dinâmica e mutante, inserido em um contexto de transformação constante.

A questão do sujeito moderno como fundamento dos direitos humanos mostra-nos ser preciso ressignificar o conceito de cidadania (DELUCHEY, 2017). E o caminho mais viável é o da luta política. Santos (2013) relata como no século XIX, o discurso dos direitos humanos separou-se da tradição revolucionária e passou a ser concebido como uma gramática despolitizada de transformação social, uma espécie de "antipolítica". O Estado assumiu o monopólio da produção do direito e da política, perante o qual assumimos a posição de destinatários passivos. Tal ilusão resultou em efeitos de isolamento, no esvaziamento do 
espaço público como campo de luta política, de retomada de discussão do conflito, do dissenso, do enfrentamento das diferenças. Entretanto, movimentos sociais recentes, ao incorporarem a linguagem dos direitos humanos como estratégia de luta e resistência, têm avançado nesse sentido, produzindo, conforme observa Merry (2011), uma nova consciência sobre esses direitos e gerando ações emancipatórias dos sujeitos a partir de um novo entendimento sobre a pessoa e seus atos, uma espécie de "empoderamento".

Zúñiga (2011), por sua vez, raciocina o processo de reconceitualização contemporânea da cidadania, principalmente engendrado pelo movimento feminista, a partir da inclusão do enfoque de gênero naquele conceito, trazendo o problema da subjetividade e sua influência na emergência de novos modelos de cidadania, dentre os quais o de cidadania como "empoderamento". A noção de empoderamento surgiu nos anos 70, em um contexto de crítica aos pressupostos em que se assentou a Modernidade, entre eles o modelo de Estado centralizado, a fórmula da representação política e a simbolização liberal-individualista do sujeito e da política como simples agregação de interesses, cenário em que se entrecruzam demandas por maior participação democrática em níveis locais de grupos excluídos. A ideia de "empoderamento" - que significa emancipação política - busca corrigir as falências da democracia liberal em um contexto de revitalização da cidadania. Implica fazer surgir poder em um grupo quanto à capacidade de controle das decisões que afetam a vida em comunidade. A pobreza e a exclusão social constituem espécies de "desempoderamento", mas não são apenas uma questão do mínimo de acesso ou consumo, como se costuma conceber. 0 "empoderamento" está ligado à participação, à autonomia e ao bem-estar, ideias que formam parte do ideário moderno. Desconstrói-se, assim, a tradição individualista de atomização dos sujeitos ao delegar à coletividade os processos de tomada de decisões e reconhecer o protagonismo dos grupos sociais nas relações de poder, além de permitir a reformulação da noção limitada de cidadão - o cliente consumidor descrito por Habermas - para um tipo-ideal de cidadão participativo, impulsionando a transformação de uma política com maior ingerência de todos os sujeitos. A cidadania como "empoderamento" retoma a dimensão do conflito político que o 
pensamento liberal reduziu à mera negociação sobre a distribuição dos benefícios sociais entre os grupos e o marco do fenômeno de sacralização do consenso.

Deluchey (2017) afirma que temos duas vias possíveis de enfrentamento das violações aos direitos humanos: uma focada no problema (via policial), e outra que considera primordialmente o conflito (via política). A primeira - mais consolidada hoje e ligada à governamentalidade neoliberal e às ciências e técnicas jurídicas (supostamente neutras) - concebe os direitos humanos como problemas de ordem técnico-gerencial. Os textos normativos constantes nos tratados internacionais e nas cartas constitucionais servem de guia para um horizonte comum supostamente pacificado, o que, por sua vez, pode ser atingido por meio de uma gestão pública competente e séria, com políticas públicas de qualidade e uma governança calcada no tripé eficiência/eficácia/efetividade. Todavia, defende que não basta gerenciar direitos humanos para garanti-los. É que a gestão policial dos direitos humanos acaba reduzindo-os a uma dimensão apolítica e falsamente universal, que promove a conversão dos direitos políticos (frutos das lutas sociais) em direitos humanitários, segundo a lógica dos direitos humanos como consenso pós-político, em detrimento do protagonismo político. Para este autor, a saída reside na devolução dos direitos humanos à sua universalidade por meio da re-politização, isto é, abordá-los sob a ótica do conflito político, verdadeiro motor da história, dando oportunidade à expressão de um "desentendimento", tal como definido por Rancière (2014). Significa reconhecer que não existe consenso e, finalmente, reinstaurar a problemática do cidadão universal.

A refundação da cidadania como projeto político para emancipação dos sujeitos pelos direitos humanos também é defendida por Žižek (2010), para quem os direitos universais são uma "ficção simbólica", pois universalizam o acesso a direitos, sem no entanto, universalizar o gozo desses direitos. Além disso, a universalização essencializa traços contingentes historicamente condicionados, o que acaba com a própria universalidade, com o sentido do comum. 0 sujeito contemporâneo experimenta a si mesmo como algo desnaturalizado, na medida em que tem sua identidade étnica - até mesmo sua preferência sexual - como algo já escolhido, normalizado. 0 direito define quem é sujeito de direito e o 
indivíduo tem de se determinar conforme esse padrão. Acredita, contudo, num retorno à universalidade através da refundação desse conceito, pois os direitos humanos universais, longe de serem pré-políticos, "designam o espaço preciso da politização propriamente dita, eles equivalem ao direito de universalidade como tal" (Žižek, 2010, p. 28). Admite, com isso, a universalização como instrumento de luta política para o resgate da dimensão do comum, da igualdade material, em detrimento das categorizações e da hegemonização do homem.

Negri (2000) também propõe uma nova maneira de pensar a universalidade. Afirma que o corpo é uma dimensão irredutível, produtora de sua própria lei, o ponto central e final de toda constituição do mundo. Cada um é sua própria obra de arte, cuja experiência subjetiva singular deve ser travada contra o universal. Em vez de universalidade, propõe o conceito de "multitude" como um "universal" que reúne todas as universalidades não-substanciais, de maneira a equiparar o dominante ao dominado.

O pensamento de tais autores nos leva a inferir que os direitos humanos, para atuarem como vetores de emancipação, precisam explodir as categorias hegemônicas, a começar pela do "sujeito universal", a partir da qual, inversamente, se definem os "não-sujeitos". 0 discurso de que há direitos humanos naturais retira dos homens a dimensão do político e os exclui do espaço de luta no qual os direitos do homem são conquistados (ao invés de naturalmente adquiridos), provocando desarticulação e despolitização (efeitos de isolamento). Por outro lado, ao se impor aos homens padrões de comportamento universais, naturaliza-se a hierarquização social na medida em que indivíduos são separados em categorias fixas e opostas: normal/anormal, rico/pobre, branco/negro, homem/ mulher, heterossexual/homossexual, cidadão/inimigo, instaurando-se uma ordem do visível e do invisível, a vida nua como modo de subjetivação. Serão emancipadores os direitos humanos quando concebidos como instrumentos de subjetivação política, de retomada do conflito no espaço do debate democrático, de retomada do "desentendimento" fundador da política. Tal reflexão se faz necessária para que possamos refundar os direitos do homem e a universalidade, entendendo-a não como um conceito absoluto, mas como uma construção do social em constante pro- 
cesso de transformação e como instrumento de resistência que permite aos indivíduos o exercício de sua liberdade como legítimos sujeitos de direito. Acreditamos que assim será possível abrir caminhos para uma compreensão crítica e emancipadora do sujeito, que nos permita pensá-lo em termos de igualdade material e a partir de uma universalidade não-substancial. Ou nas palavras de Wallerstein (2007, p. 84):

É preciso que universalizemos nossos valores particulares e, ao mesmo tempo, que particularizemos nossos valores universais, num tipo de troca dialética constante que nos permita encontrar novas sínteses que, naturalmente, são instantaneamente questionadas. Não é um jogo fácil.

\section{NOTAS}

1 De acordo com Foucault (2010), trata-se de um tipo de racismo biológico-social que visa a defender a sociedade contra os perigos biológicos de uma sub-raça ou contrarraça constituída pelo poder, e que servirá de estratégia para o "conservadorismo social". Surge com a substituição da "luta de raças" pela "luta de classes", em que o tema da guerra histórica (batalhas, invasões, vitórias e derrotas) é substituído pelo tema biológico, pós-evolucionista, da luta pela vida. Não mais batalha no sentido guerreiro, mas luta no sentido biológico: diferenciação das espécies, seleção do mais forte, manutenção das raças mais bem adaptadas, etc. 0 Estado passa a ser o protetor da integridade, da superioridade e da pureza da raça. Passa-se do plural das raças para o singular da raça. Seu fundamento é a proteção biológica da raça pelo racismo. 0 perigo biológico representado pelo criminoso, pelo anormal, pelo heterogêneo, precisava ser combatido por meio da eliminação do inimigo de raça, de forma a assegurar a higiene, a pureza e a integridade da raça que compunha a sociedade ordenada.

2 Esta questão remete ao paradoxo insuperável da definição liberal dos direitos humanos, apresentado por Hannah Arendt no livro Origens do Totalitarismo: "Se um ser humano perde o seu status político, deve, de acordo com as implicações dos direitos inatos e inalienáveis do homem, enquadrar-se exatamente na situação que a declaração desses direitos gerais previa. Na realidade, o que acontece é o oposto. Parece que o homem que nada mais é que um homem perde todas as qualidades que possibilitam aos outros tratá-lo como semelhante". (ARENDT, 1989 [1949]: 334).

\section{REFERÊNCIAS}

AGAMBEN, Giorgio. Homo Sacer: o poder soberano e a vida nua I, Profanações. Belo Horizonte: Ed. UFMG, 2010.

ARENDT, Hannah. As origens do totalitarismo. São Paulo: Cia. das Letras, 1989 [1949]. 
BOMFIM, Thiago. Sujeito de direito e direito sem sujeito. Jan. 2003. Disponível em: <http://www.unifacs.br/revistajuridica/arquivo/edicao_janeiro2003/ convidados/convidado02.doc>. Acesso em: 25 jul. 2014.

BRAGATO, Fernanda Frizzo. Para além do discurso eurocêntrico dos direitos humanos: contribuições da descolonialidade. 2014. Disponível em: <http:// siaiap32.univali.br/seer/index.php/nej/article/view/5548>. Acesso em: 15 Mar.2017.

CLAVERO, Bartolomé. Derecho global: por una historia verosímil de los derechos humanos. Madrid: Trotta, 2014.

DELUCHEY, Jean-François Y. Da gestão do humano à refundação da cidadania universal, In: VIII Encontro da ANDHEP - Políticas Públicas para a Segurança Pública e Direitos Humanos. São Paulo: Associação Nacional de Direitos Humanos Pesquisa e Pós Graduação. ANDHEP, 2017.v.1.p. 2403 - 2421. Disponível em: <http://www.encontro2014.andhep.org. br/resources/anais/1/1397579254_ARQUIVO_Jean-FrancoisDeluchey-ANDHEP2014-Grupo10.pdf>. Acesso em: 25 mar.2016.

DELUCHEY, Jean-François Y. 2016. “Sobre Estratégias e Dispositivos Normativos em Foucault: Considerações de Método". Revista da Faculdade de Direito da UFG, v. 40, 2016, p. 175-196.

DONNELLY, Jack. The relative universality of human rights. Human Rights Quarterly. v. 29, n. 2, 2007, p. 281-306.

FONSECA, Márcio Alves de. Michel Foucault e o direito. São Paulo: Ed. Max Limonad, 2002.

FOUCAULT, Michel. Sobre a história da sexualidade. In: Microfísica do poder. Rio de Janeiro: Graal, 1995.

Préface. In: FOUCAULT, Michel. Dits et Écrits, Paris: Gallimard, 2001. Tomo III p. 133-136. (Une introduction à la vie non fasciste). Texto ${ }^{\circ}{ }^{189}$, 1976-1988.

. Face aos governos, os direitos humanos. In: Ditos e escritos. Rio de Janeiro: Forense Universitária, 2009. v. 6.

Em defesa da sociedade. São Paulo: Ed. Martins Fontes, 2010. 
. História da loucura. São Paulo: Ed. Perspectiva, 2012.

. A sociedade punitiva. São Paulo: Ed. Martins Fontes, 2015.

KASHIURA Júnior, Celso Naoto. Sujeito de direito e capitalismo. 2012.177 f. Tese (Doutorado em Filosofia e Teoria Geral do Direito) - Universidade de São Paulo, São Paulo, 2012.

MERRY, Sally Engle. Derechos Humanos, género y nuevos movimentos sociales: debates contemporáneos en antropología jurídica. In: CHENAUT, Victoria; GOMEZ, Madalena; ORTIZ, Héctor; SIERRA, María Tereza (Coords.) Justicia y Diversidad en América Latina: pueblos Indígenas ante la globalización. Mexico/ Ecuador, Ciesas/Flacsos, La Casa Chata, 2011.

NEGRI, (T). Carta a Raúl, sobre el cuerpo: arte y multitudo: ocho cartas. Madrid: Editorial Trotta S.A, 2000.

PIOVESAN, Flávia. Ações afirmativas no Brasil: desafios e perspectivas. 2008. Disponível em: <https://periodicos.ufsc.br/index.php/ref/article/view/S0104026X2008000300010>. Acesso em: 10 mar. 2017.

RANCIÈRE, Jacques. Who is the subject of the rights of man? Disponível em: <http://muse.jhu.edu/login?type=summary\&url=/journals/south_atlantic_quarterly/v103/103.2ranciere.pdf>. Acesso em: 14. jun. 2014.

REBOUÇAS, Gabriela Maia. 0 avesso do sujeito: provocações de Foucault para pensar os direitos humanos. Opinión Jurídica, Medellín, v. 14, n. 28, p. 45-62, jul./dez. 2015. Disponível em: <http://www.scielo.org.co/scielo.php?script=sci_ arttext\&pid=S1692-25302015000200003 > . Acesso em: 20 fev. 2017.

SAFATLE, Vladimir. 0 dever e seus impasses. São Paulo: Martins Fontes, 2013.

SANTOS, Boaventura de Sousa; CHAUI, Marilena. Direitos humanos, democracia e desenvolvimento. São Paulo: Cortez, 2013.

WALLERSTEIN, Immanuel. 0 universalismo europeu. São Paulo: Boitempo, 2007.

ŽIŽEK, Slavoj. Contra os direitos humanos. Mediações, Londrina, v. 15, n.1, p. 11-29, jan./jun., 2010. 
ZÚÑIGA Yanira. Ciudadanía y género. Representaciones y conceptualizaciones en el piensamiento moderno y contemporâneo. In: CULLETON, Alfredo; MAUÉS, Antonio; TOSI, Giuseppe; ALENCAR, Maria Luiza; WEYL, Paulo (Orgs.). Direitos Humanos e integração latino-americama. Porto Alegre: Entrementes, 2011.

Recebido em: 19-5-2017

Aprovado em: 20-12-2017

\section{Farah de Sousa Malcher}

Doutoranda do Programa de Pós-Graduação em Direito da Universidade Federal do Pará (UFPA); mestre em Direito, Políticas Públicas e Desenvolvimento Regional; pesquisadora do Centro de Estudos sobre Instituições e Dispositivos Penais (CESIP); analista Judiciário do Tribunal de Justiça do Estado do Pará. E-mail: fsmalcher@gmail.com.

Tribunal de Justiça do Estado do Pará. Rua Avertano Rocha, Campina. 66023120 - Belém, PA - Brasil

Jean-François Yves Deluchey

Doutor em Ciência Política / Políticas Públicas pela Univ. da Sorbonne Nouvelle (Paris 3); pós-doutor do PPG em Direito da PUC-Rio; professor Associado da Universidade Federal do Pará (UFPA), docente da Faculdade de Serviço Social (FASS/ICSA); docente permanente do Programa de PósGraduação em Direito (PPGD-ICJ); colaborador do PPG em Serviço Social e PPG em Ciência Política (UFPA); bolsista da fundação alemã Gerda Henkel Stiftung; coordenador do Centro de Estudos sobre Instituições e Dispositivos Punitivos (CESIP) e do grupo de pesquisa CNPq Desigualdades, Formas de Vida e Instituições no Brasil; conselheiro consular eleito da República Francesa (circunscrição de Brasília-Recife-Paramaribo, mandato 20142020); conselheiro nomeado do Conselho Estadual de Política Criminal e Penitenciária do Estado do Pará. E-mail: jfdeluchey@gmail.com

Universidade Federal do Pará, Instituto de Ciências Sociais Aplicadas. Rua Augusto Corrêa, 01, Guamá, 66075110 - Belém, PA - Brasil. 